\title{
Diffusion Bonding of Silicon Carbide for MEMS-LDI Applications
}

Michael C. Halbig, Army Research Laboratory, Vehicle Technology Directorate, Cleveland, $\mathrm{OH}$; Mrityunjay Singh, Ohio Aerospace Institute, Cleveland, $\mathrm{OH}$; Tarah P. Shpargel, QSS Group, Inc., Cleveland, OH; James D. Kiser, NASA Glenn Research Center, Cleveland, $\mathrm{OH}$

A robust joining approach is critically needed for a Micro-Electro-Mechanical Systems-Lean Direct Injector (MEMS-LDI) application which requires leak free joints with high temperature mechanical capability. Diffusion bonding is well suited for the MEMS-LDI application. Diffusion bonds were fabricated using titanium interlayers between silicon carbide substrates during hot pressing. The interlayers consisted of either alloyed titanium foil or physically vapor deposited (PVD) titanium coatings. Microscopy shows that well adhered, crack free diffusion bonds are formed under optimal conditions. Under less than optimal conditions, microcracks are present in the bond layer due to the formation of intermetallic phases. Electron microprobe analysis was used to identify the reaction formed phases in the diffusion bond. Various compatibility issues among the phases in the interlayer and substrate are discussed. Also, the effects of temperature, pressure, time, silicon carbide substrate type, and type of titanium interlayer and thickness on the microstructure and composition of joints are discussed. 


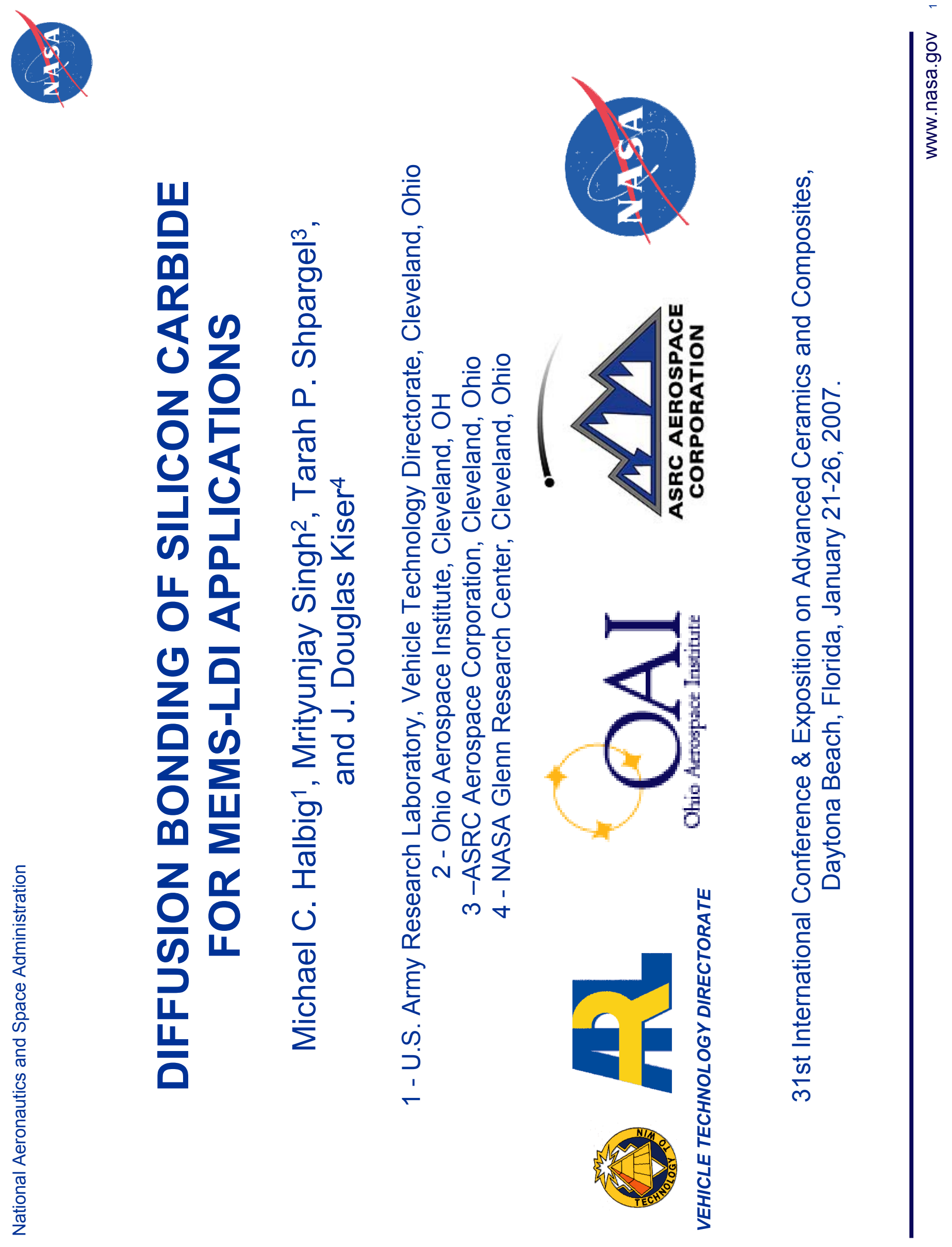




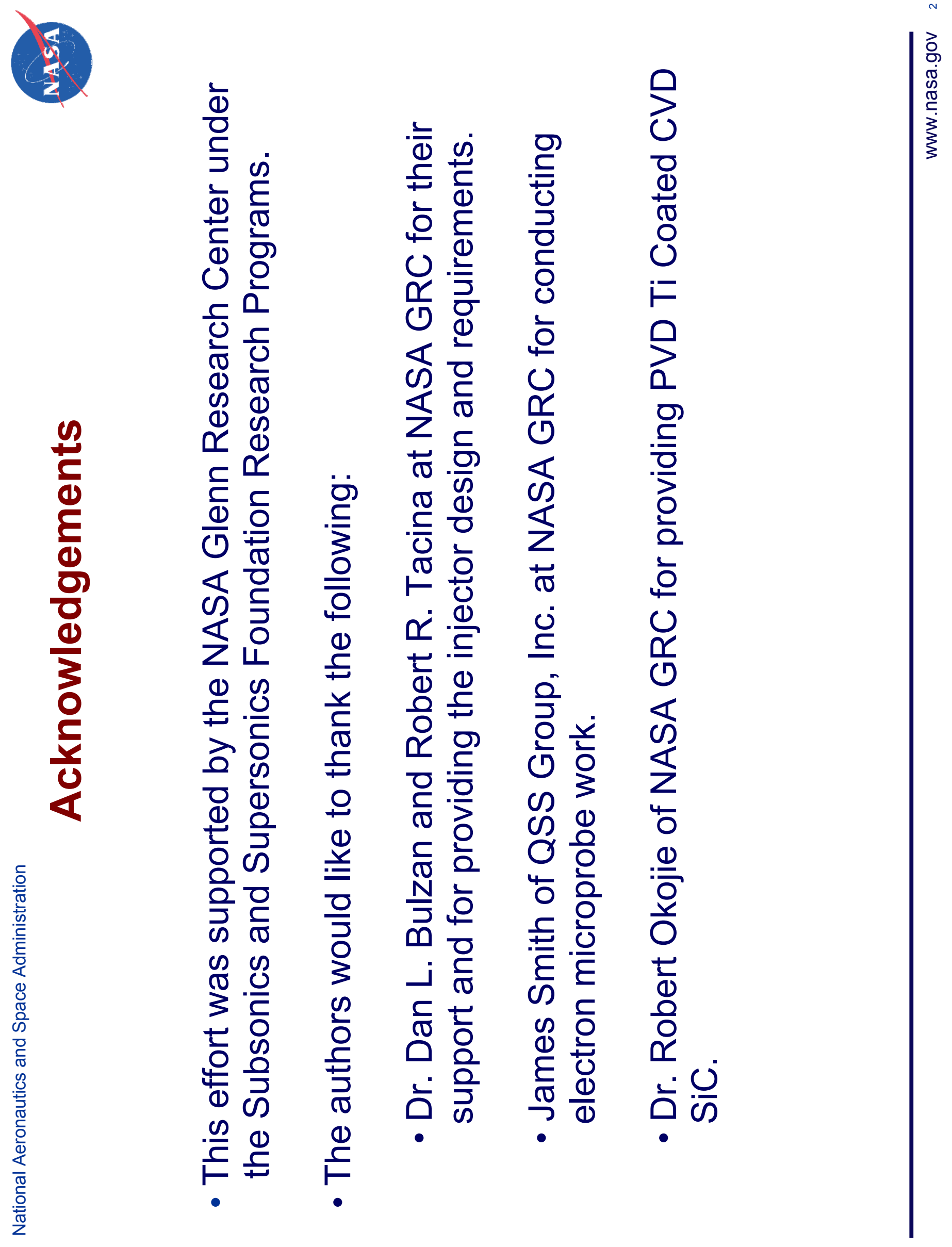


ש

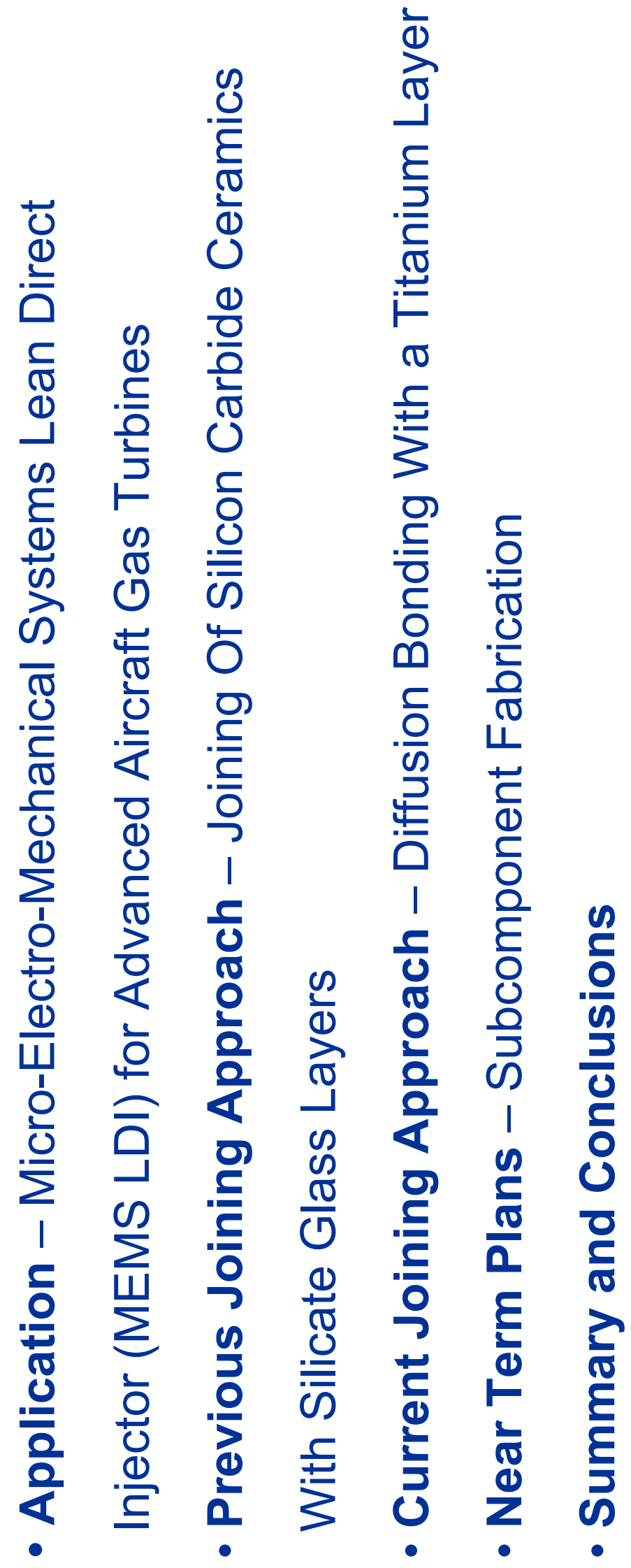




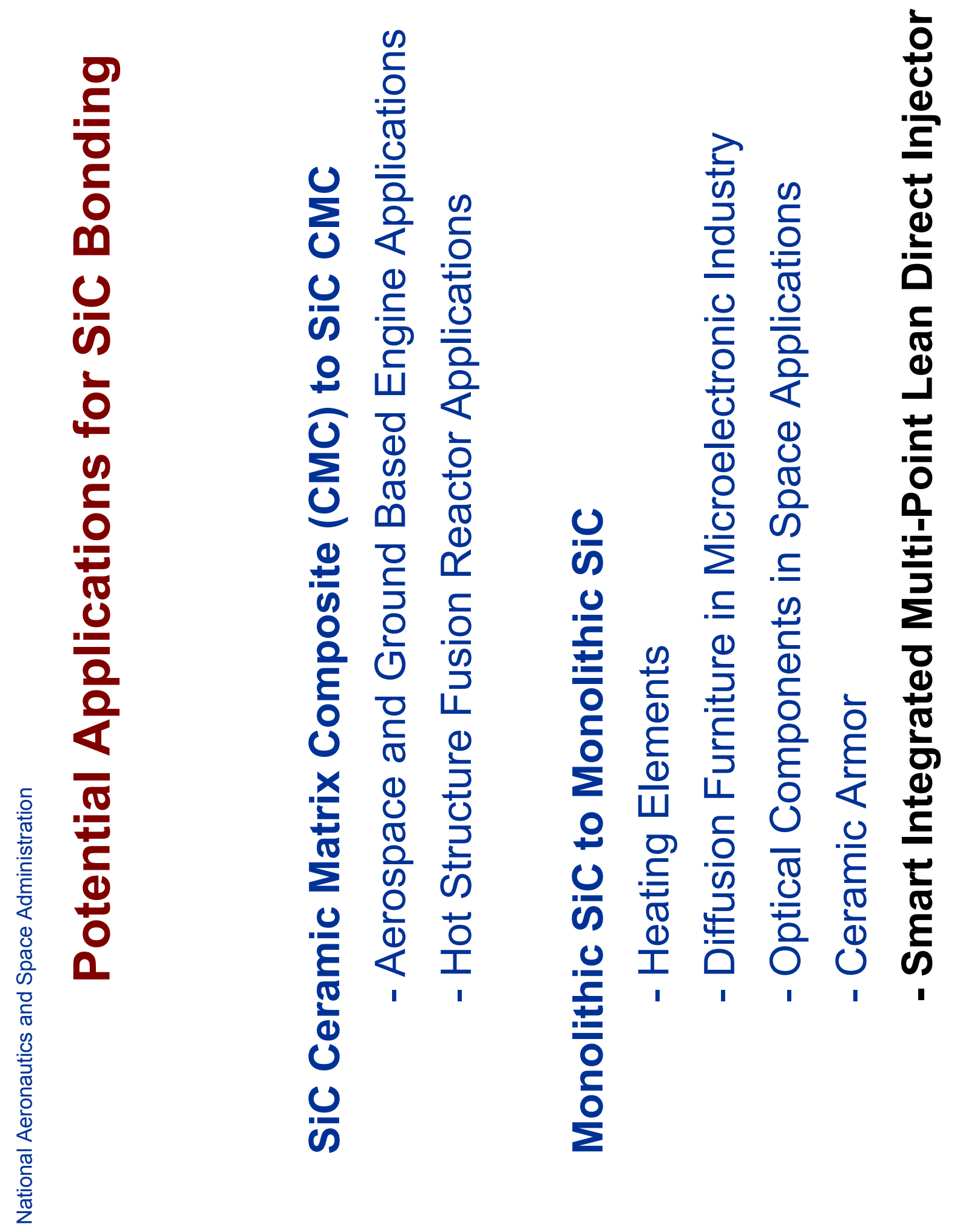




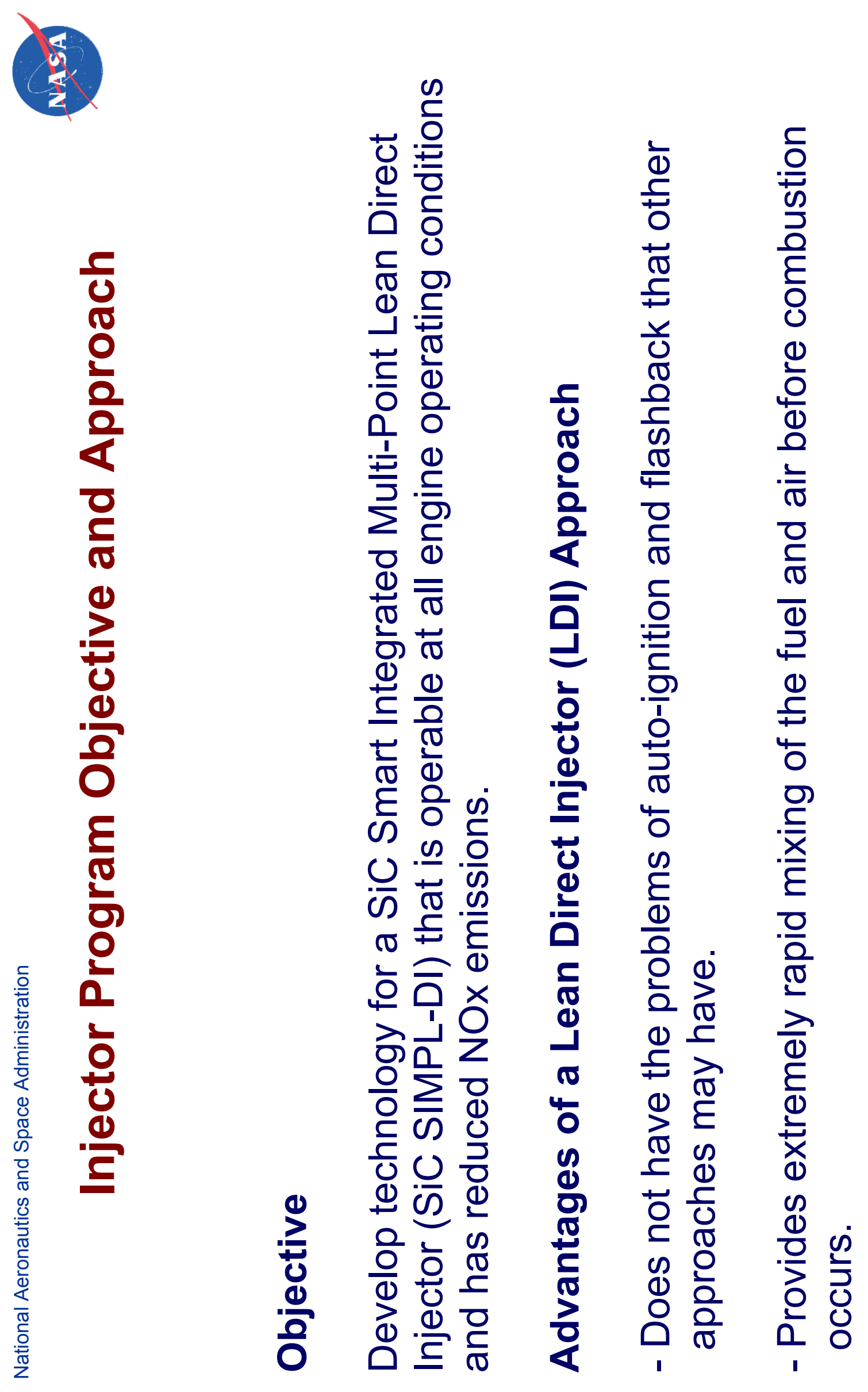




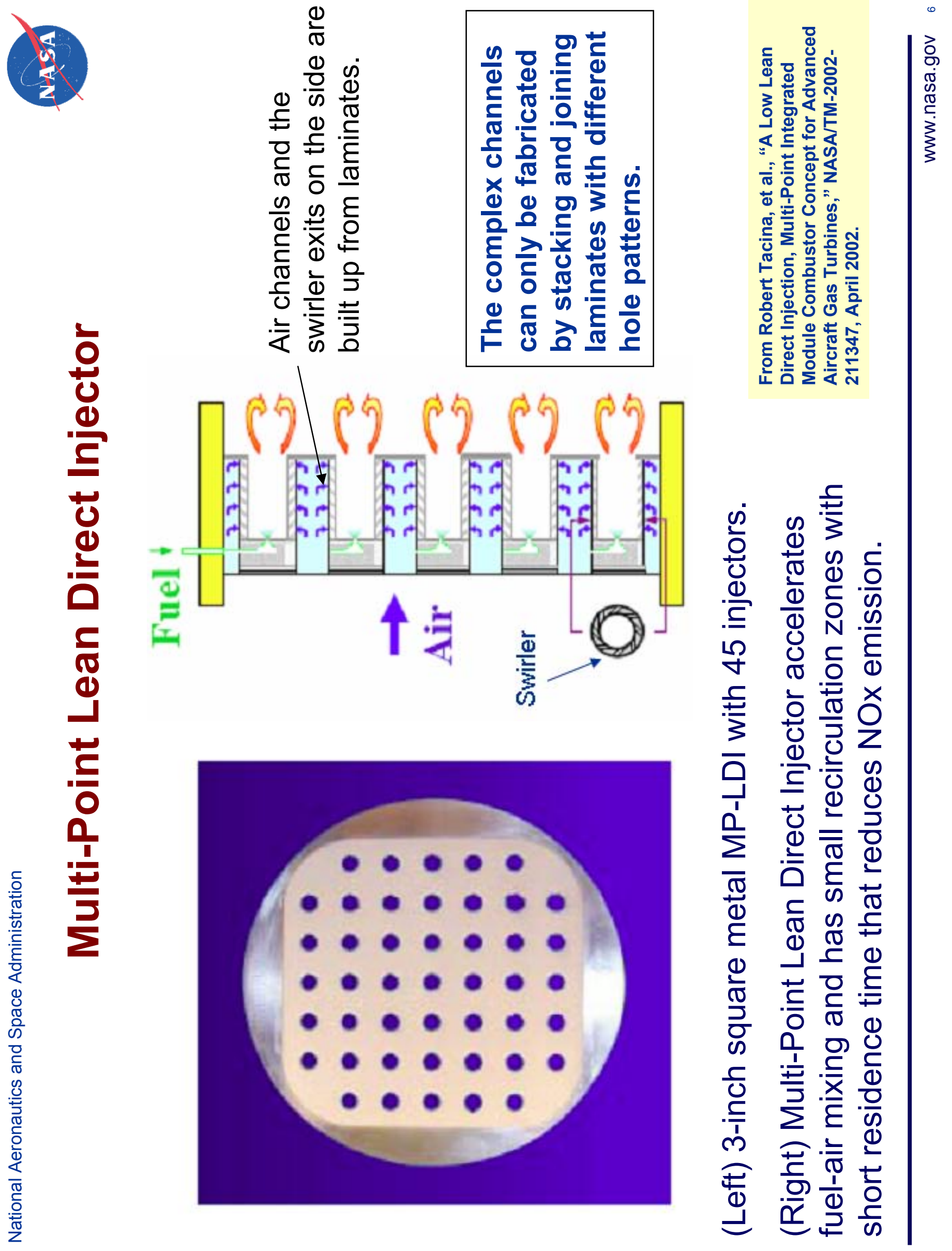



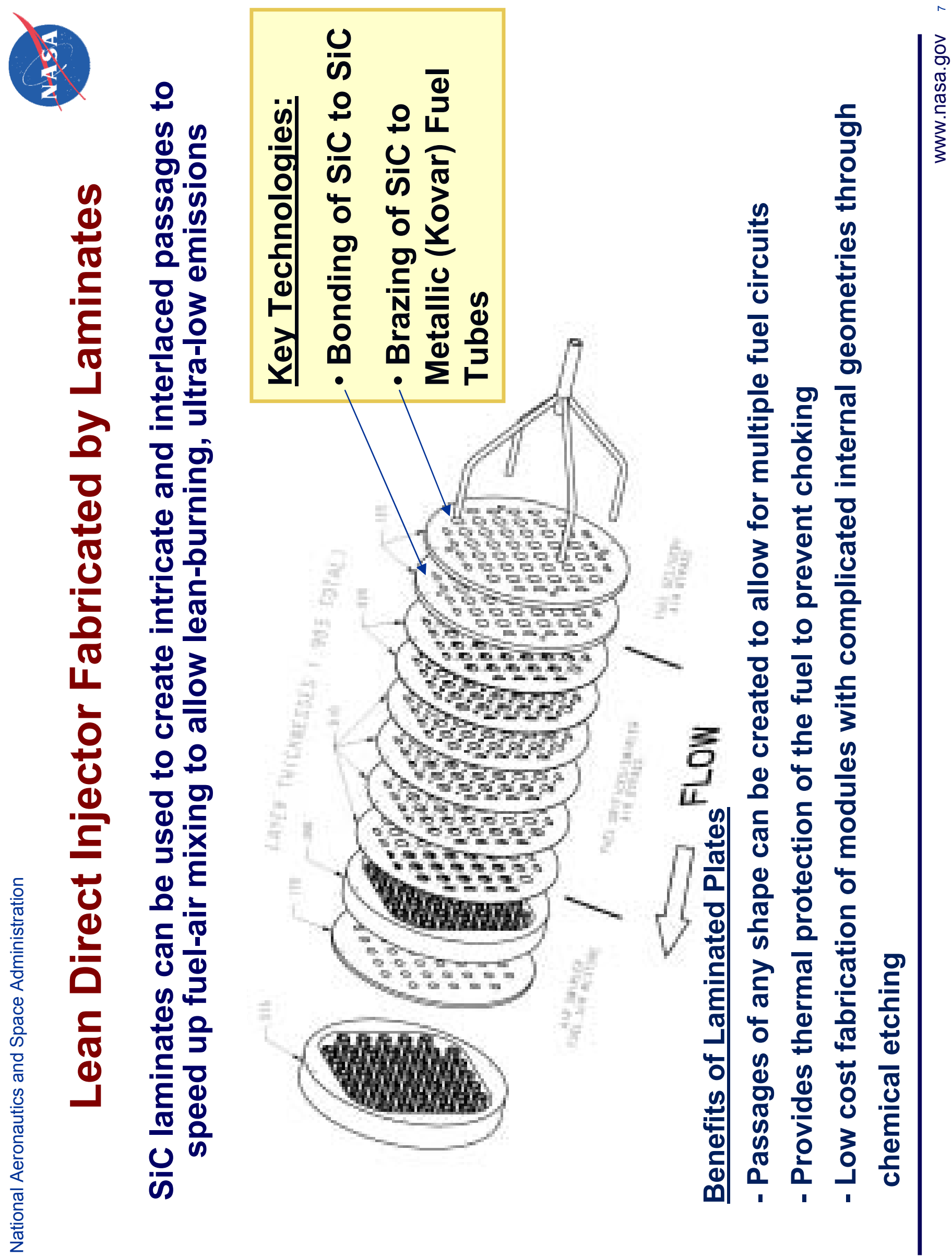


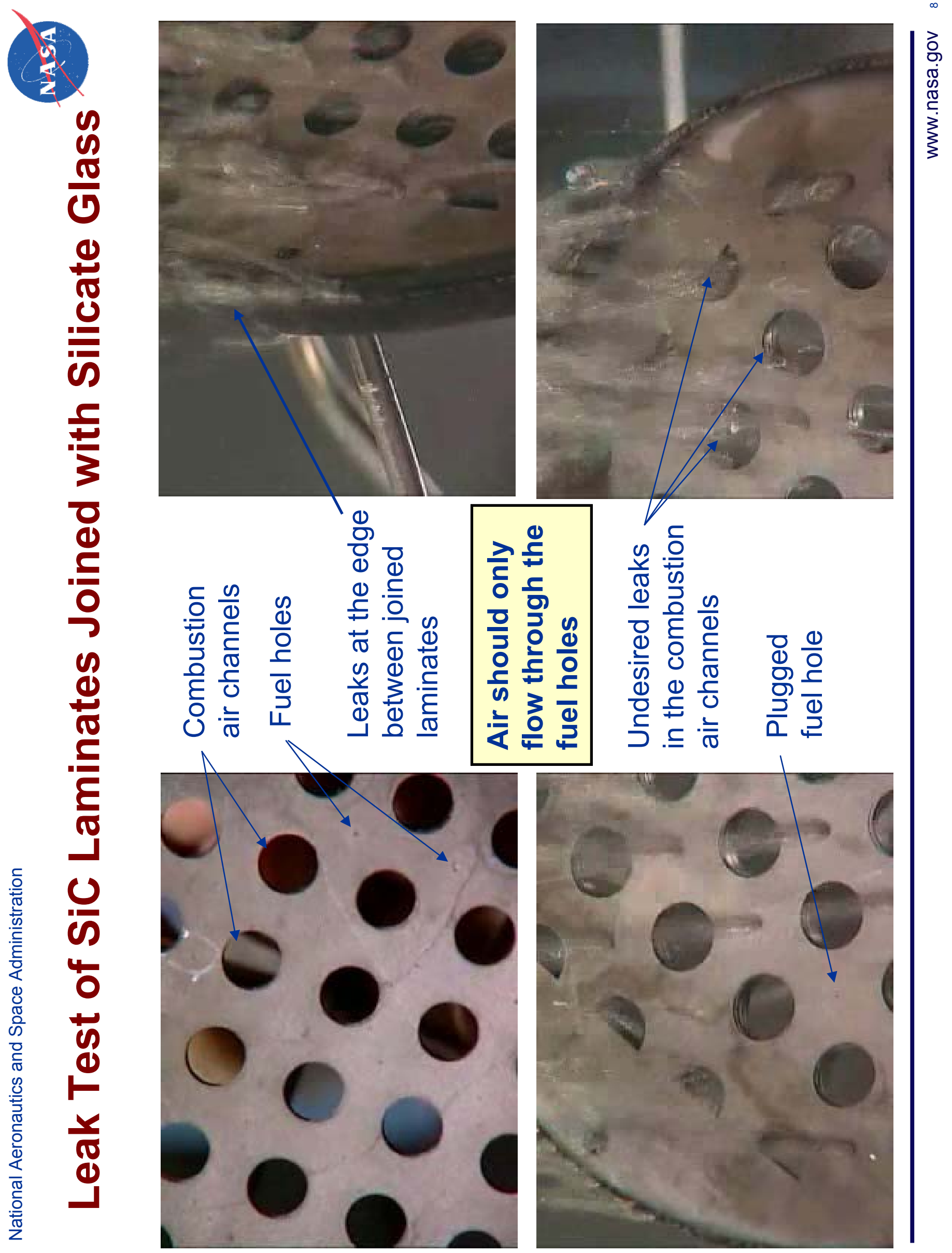




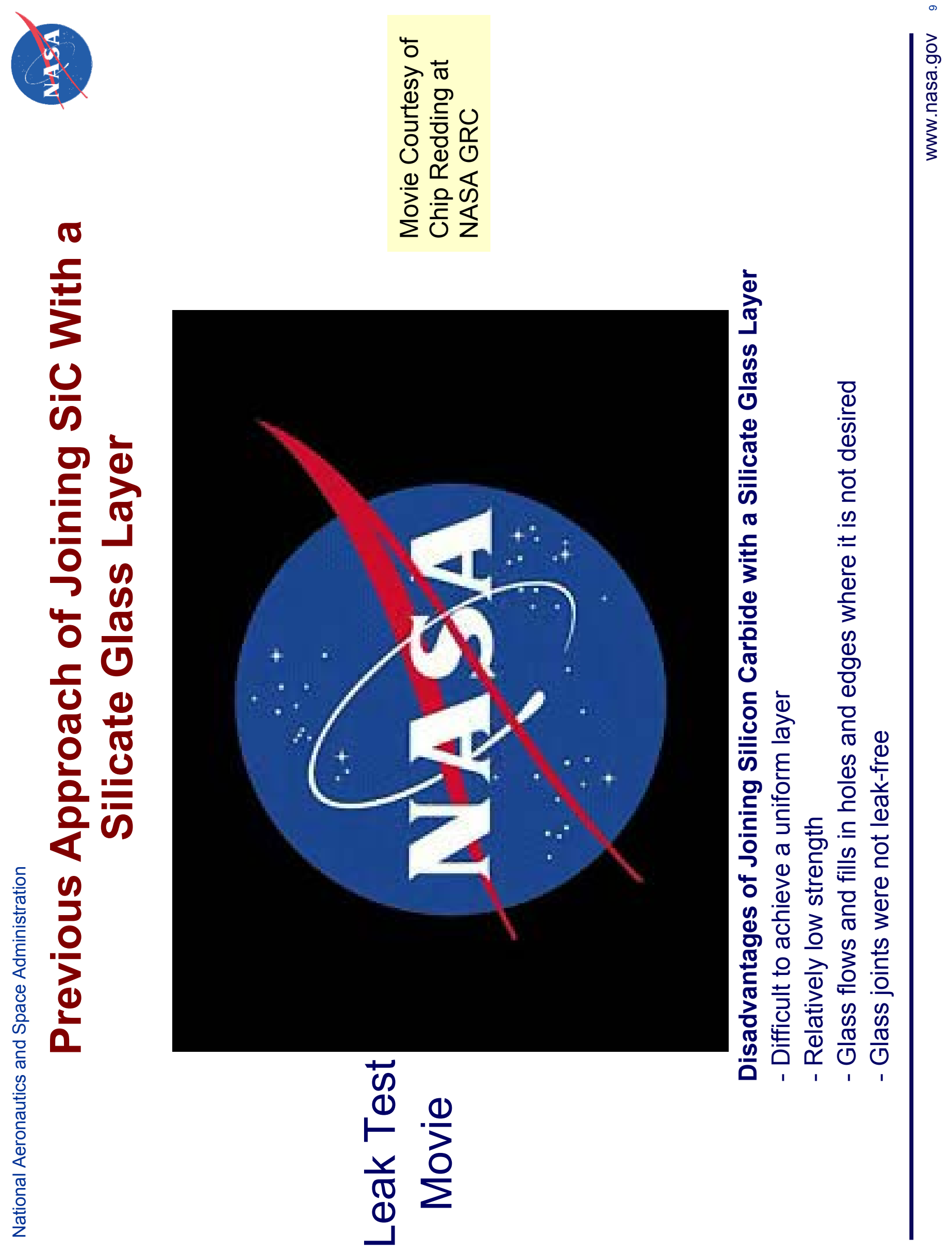




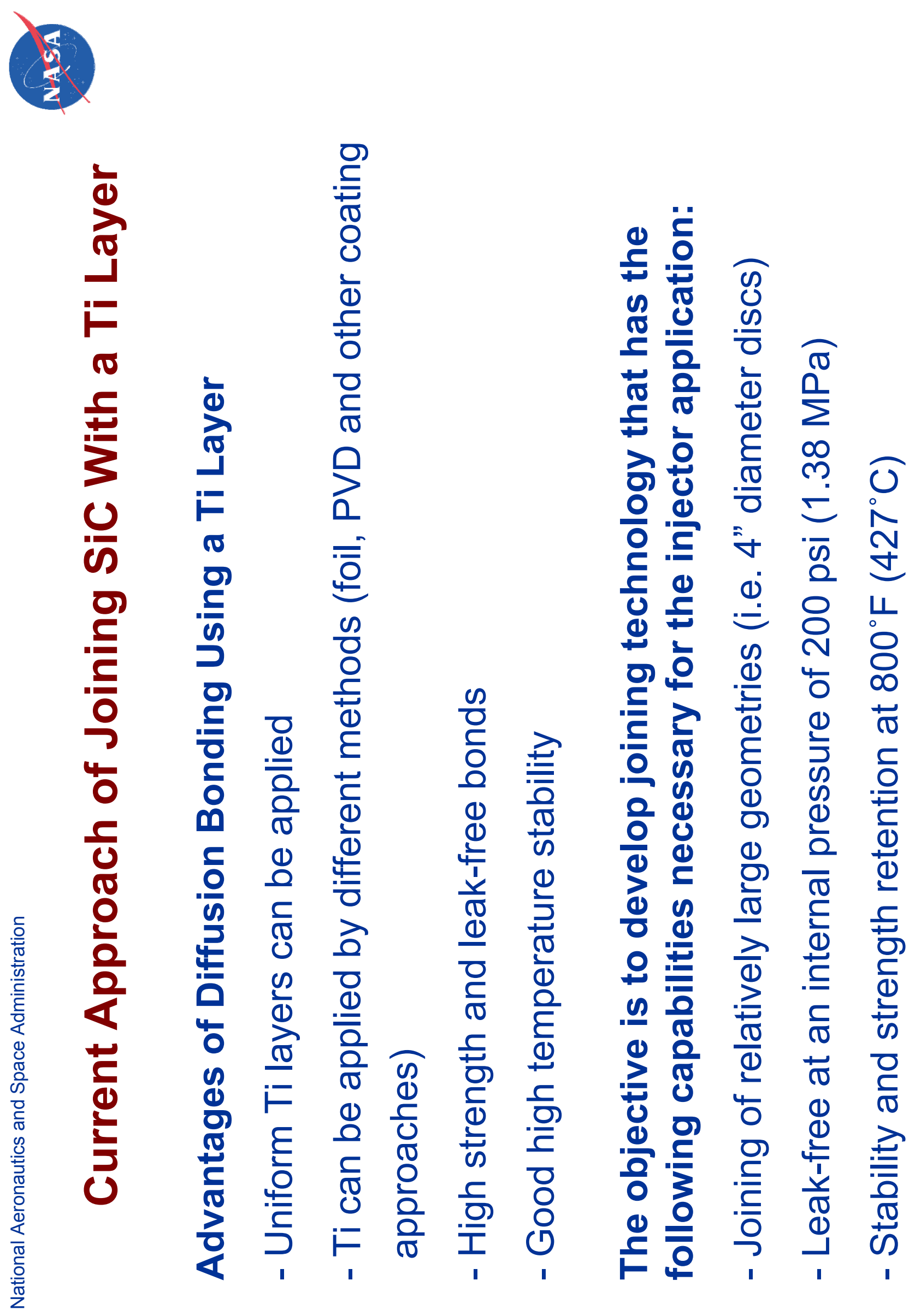




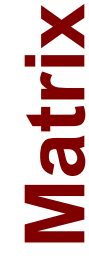

$\frac{\pi}{3}$

\begin{tabular}{ll|}
$i$ & Dे \\
\hdashline & $\overline{\bar{d}}$ \\
\hline
\end{tabular}

○

. $\frac{1}{0} \quad$ 으

$\frac{c}{0}$
$\frac{\frac{1}{u}}{E}$
$\frac{0}{2}$
$\frac{0}{2}$

을

(2) 긍

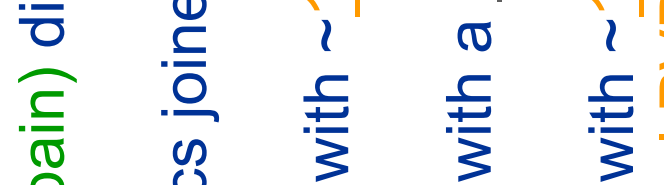

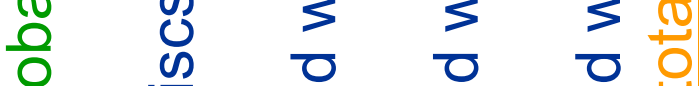

D

(1)

0

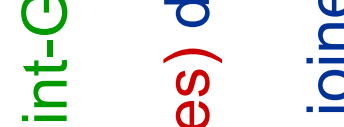

2

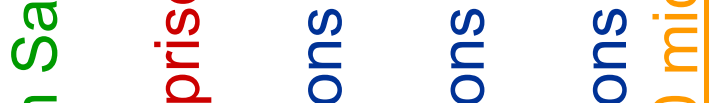

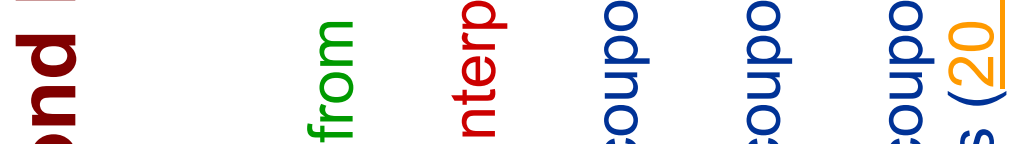

임

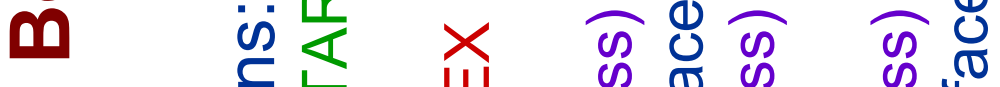

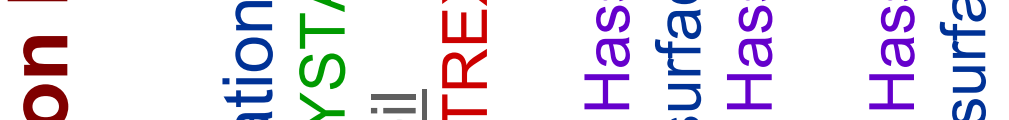

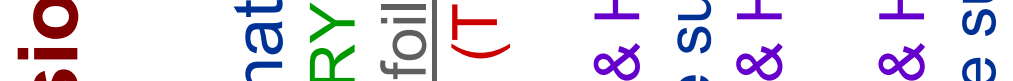

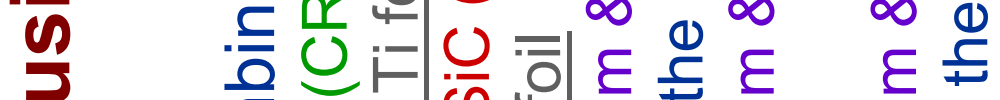

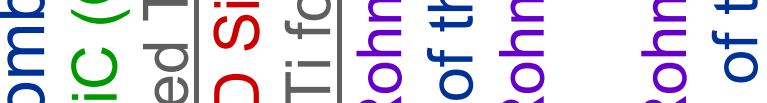

Uं

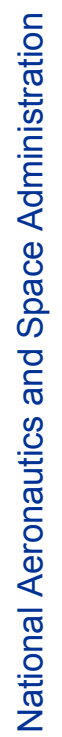
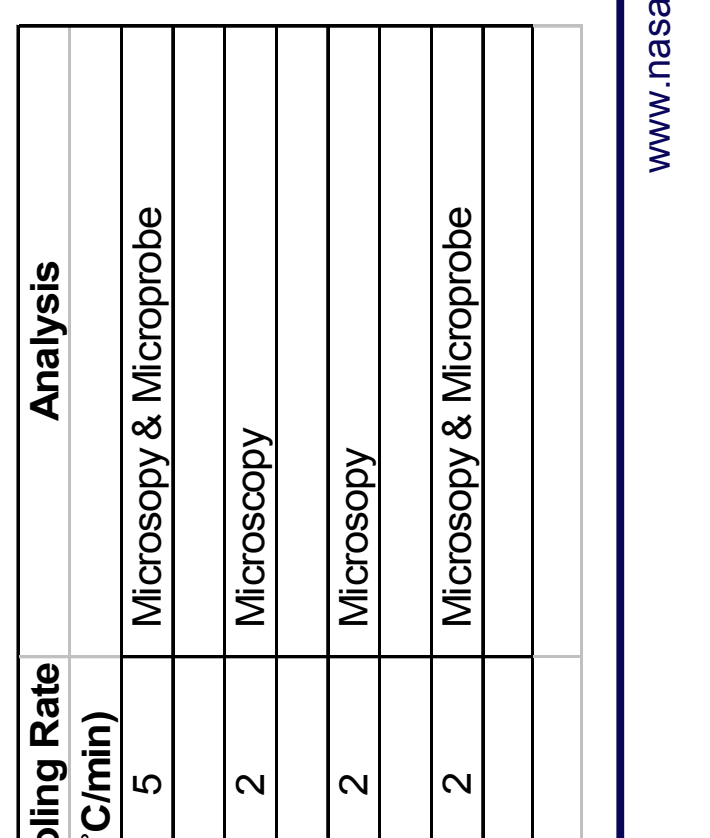

তে

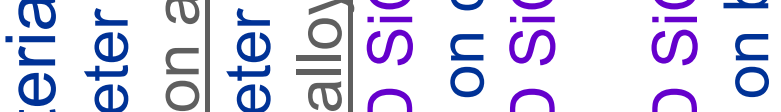

0 光

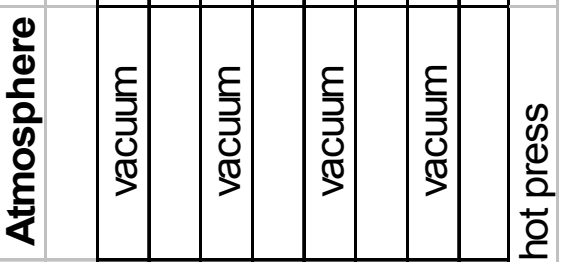

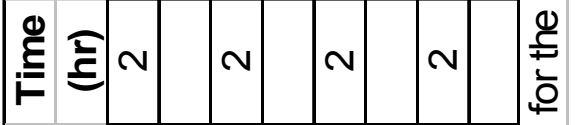

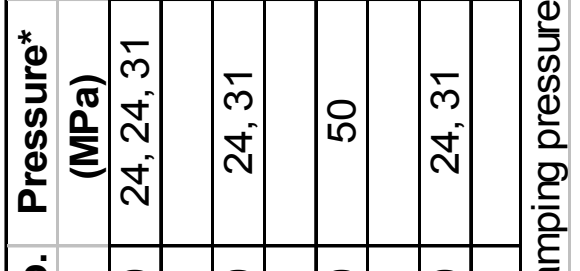

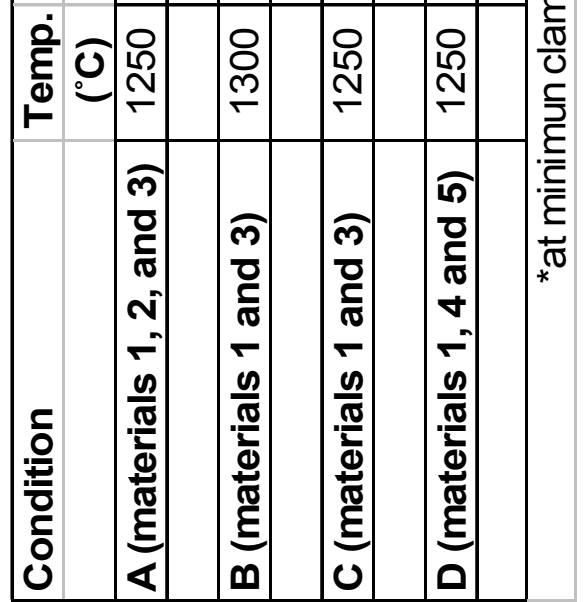




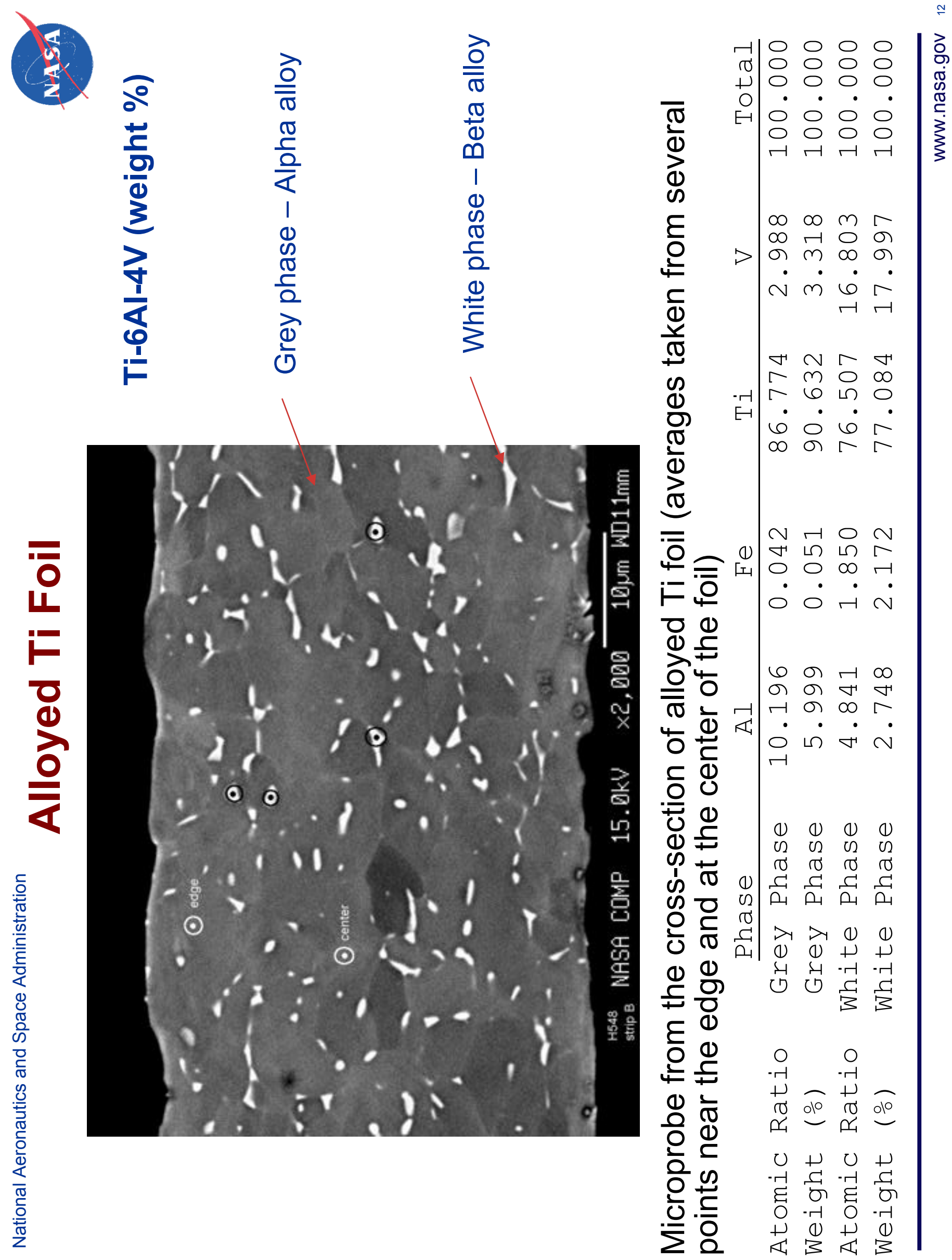




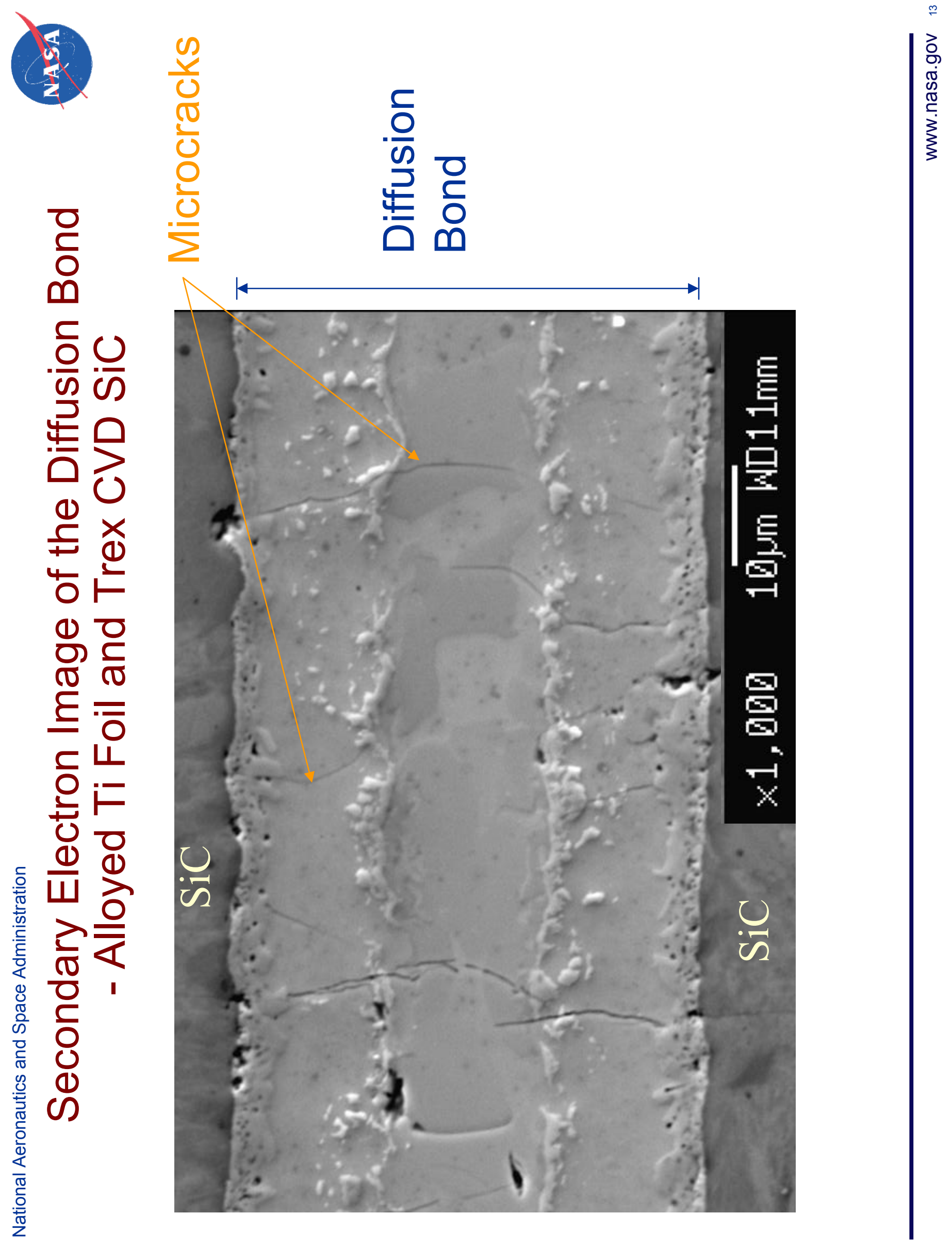




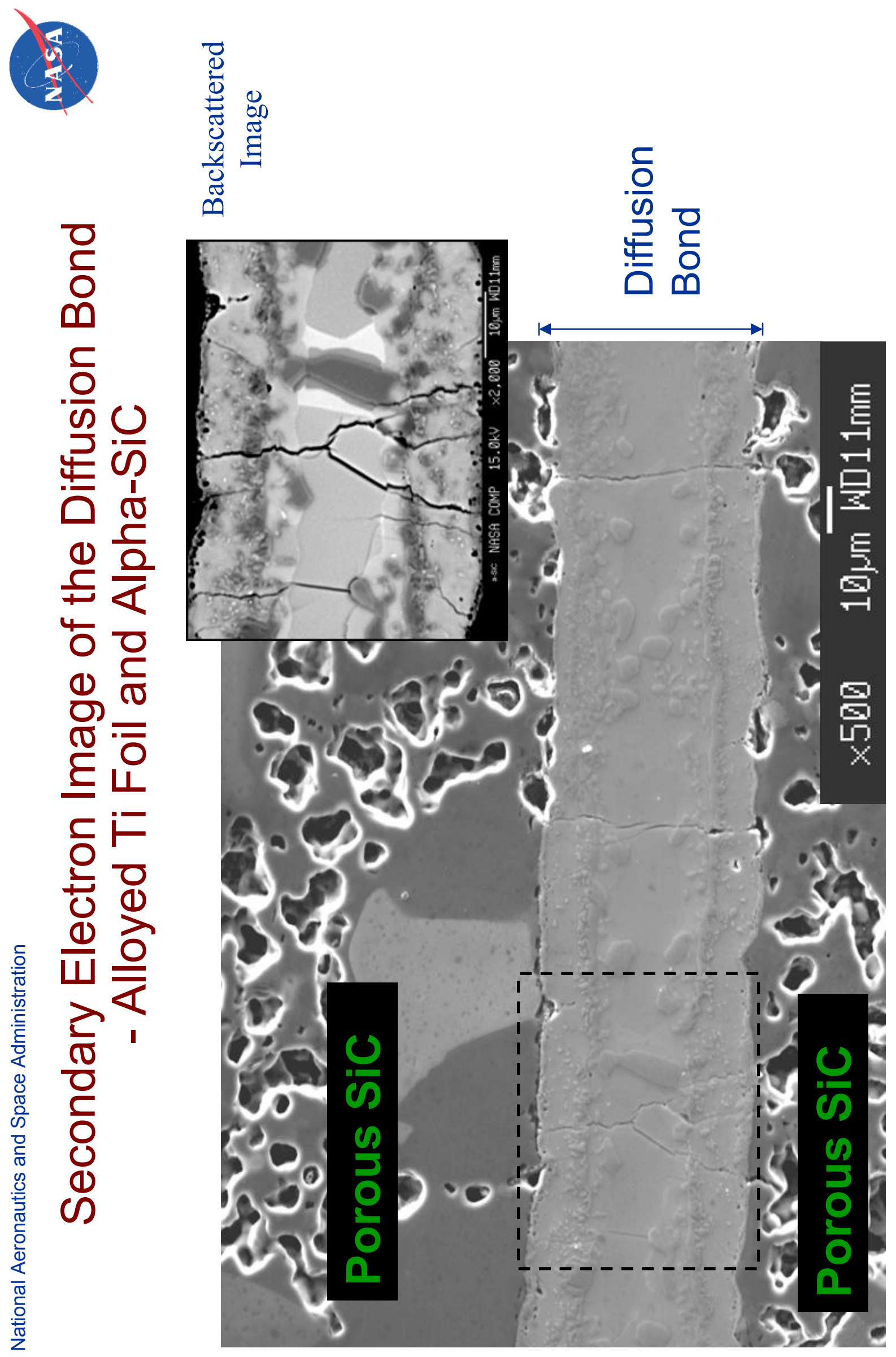




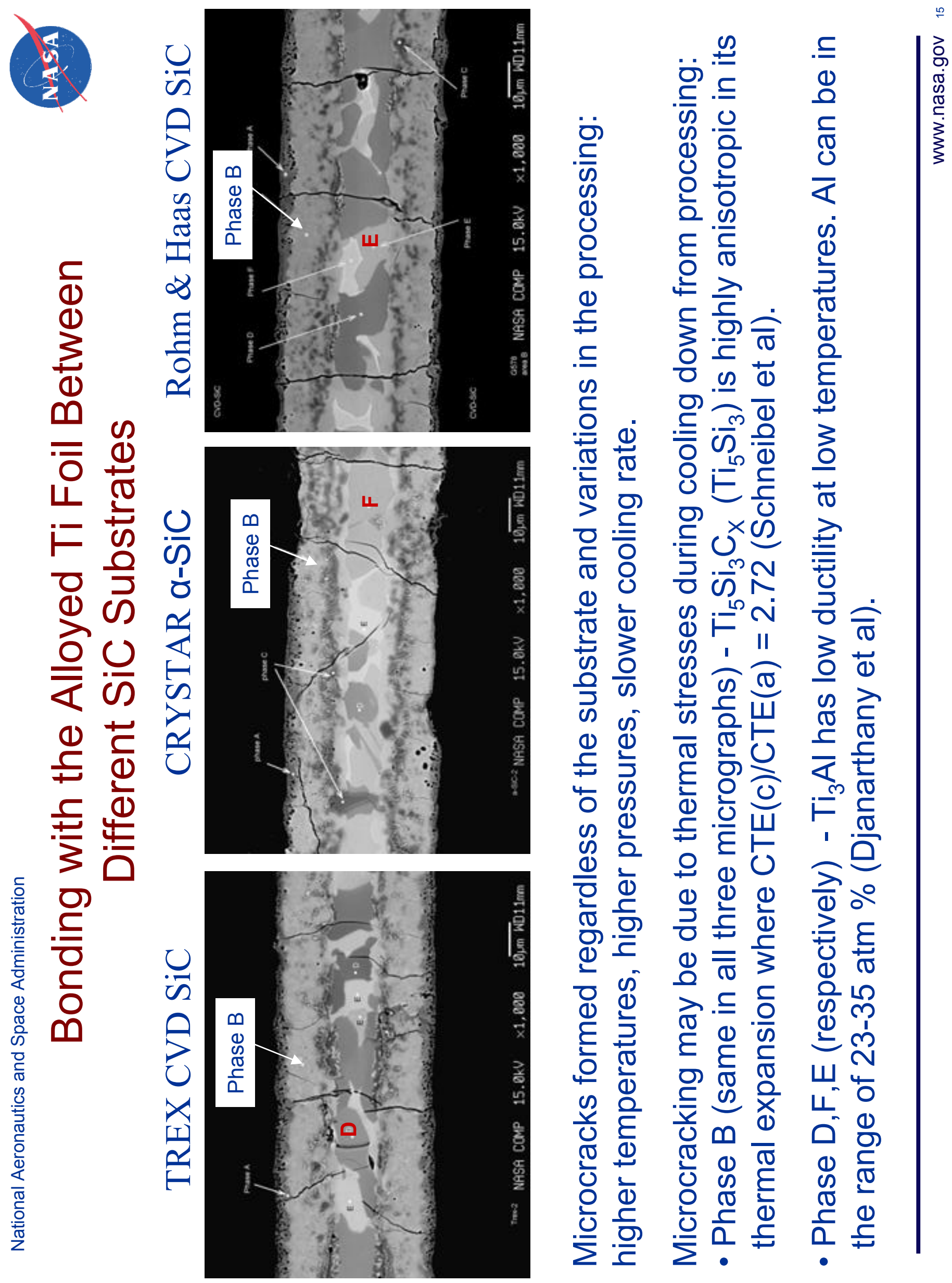




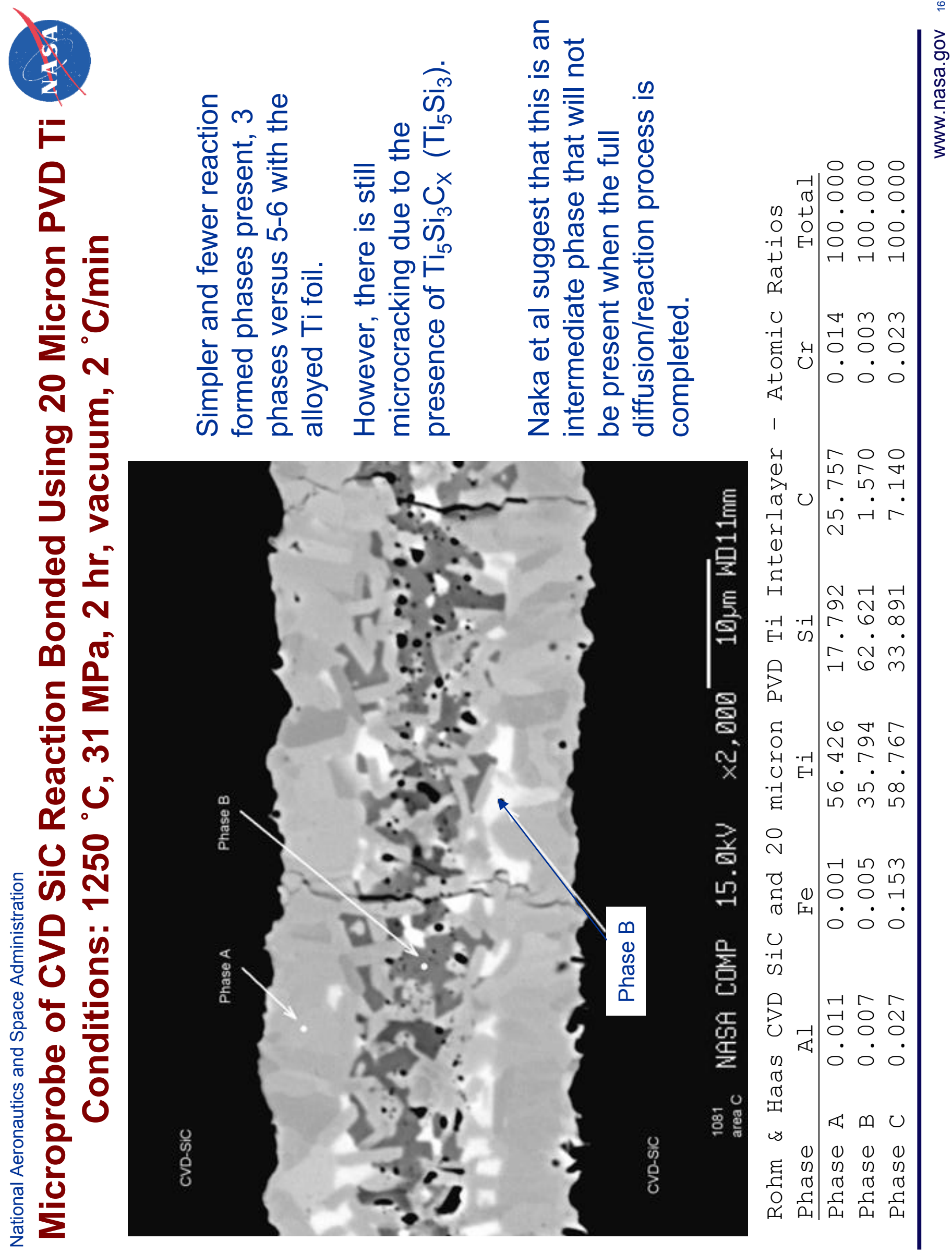




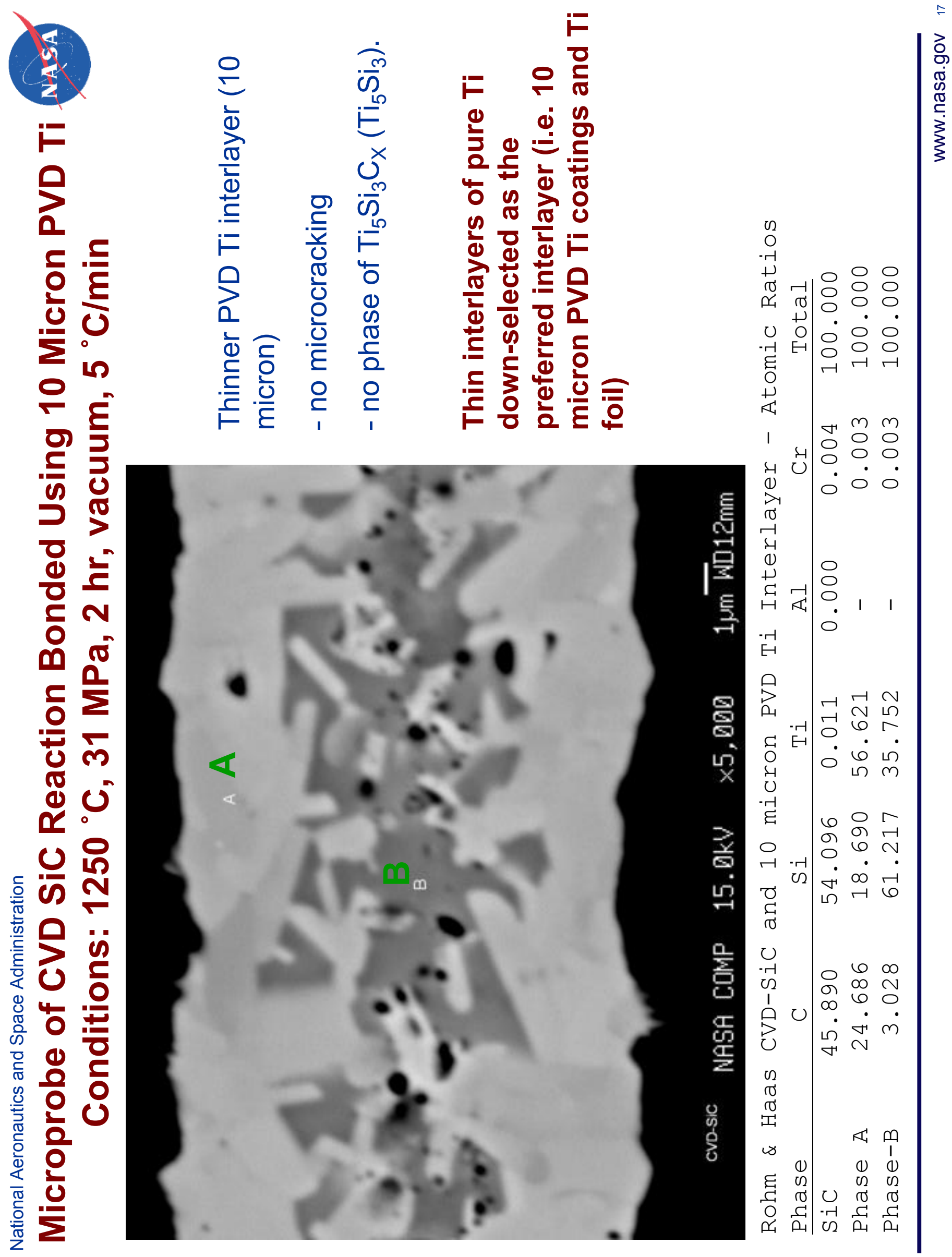




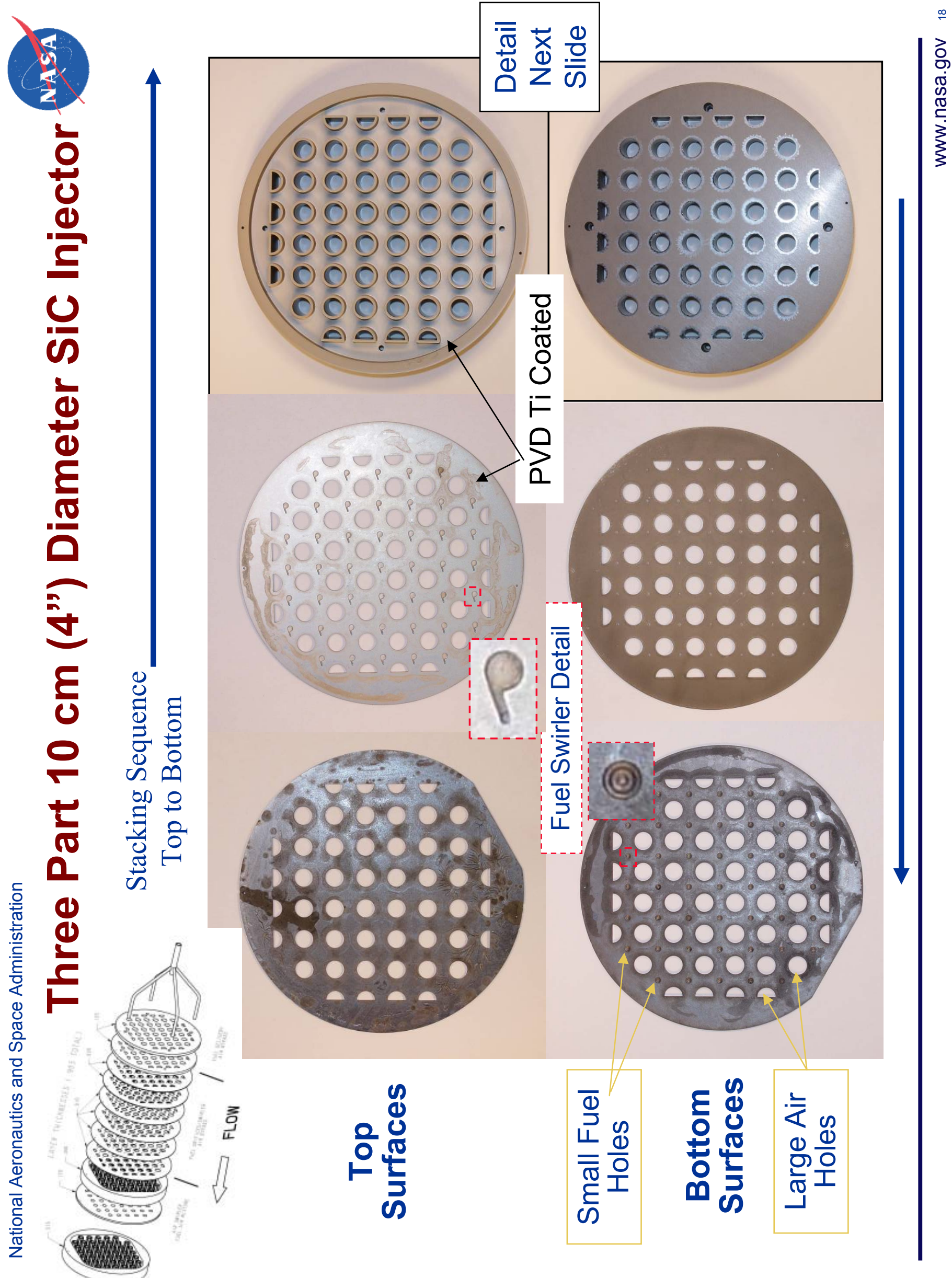




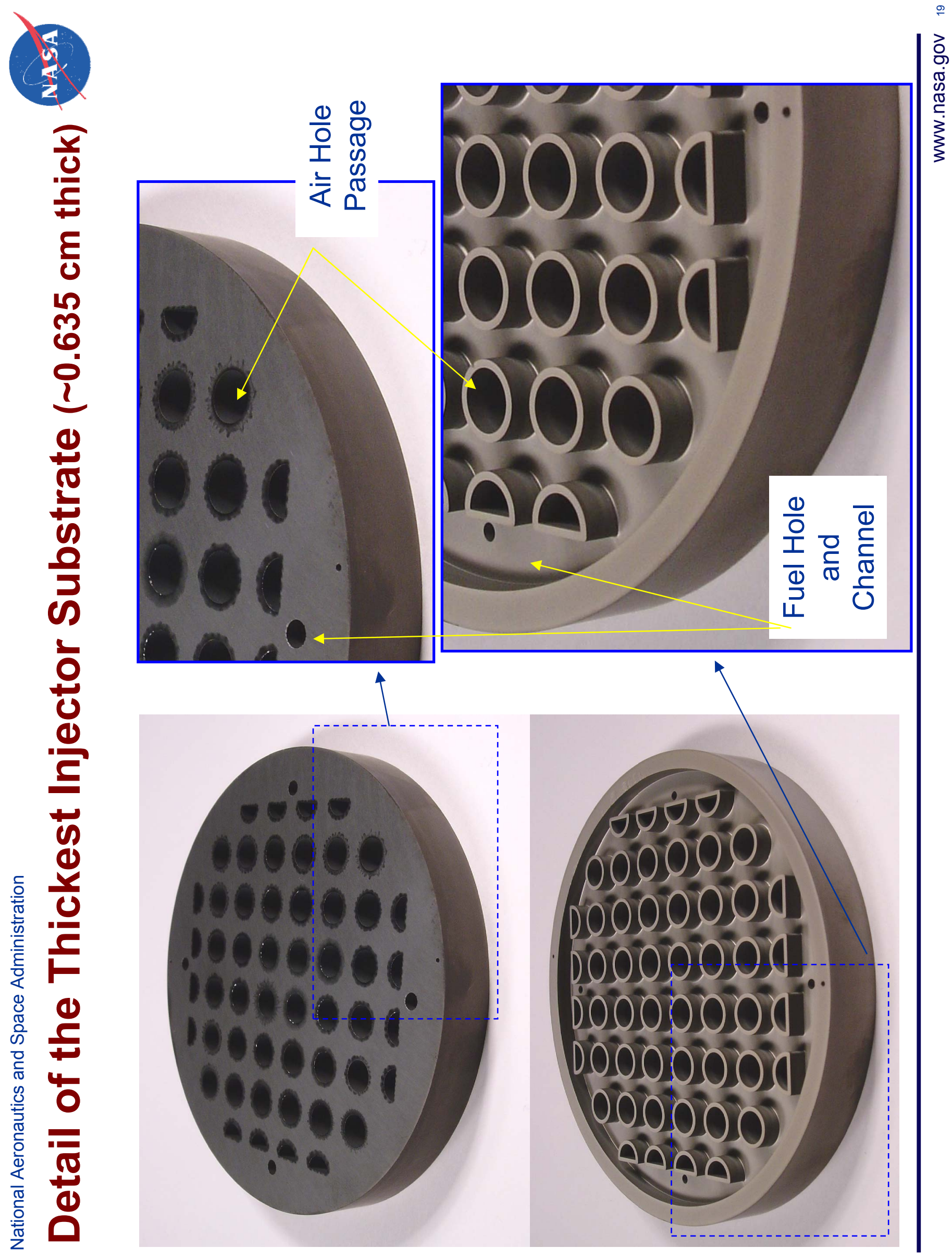




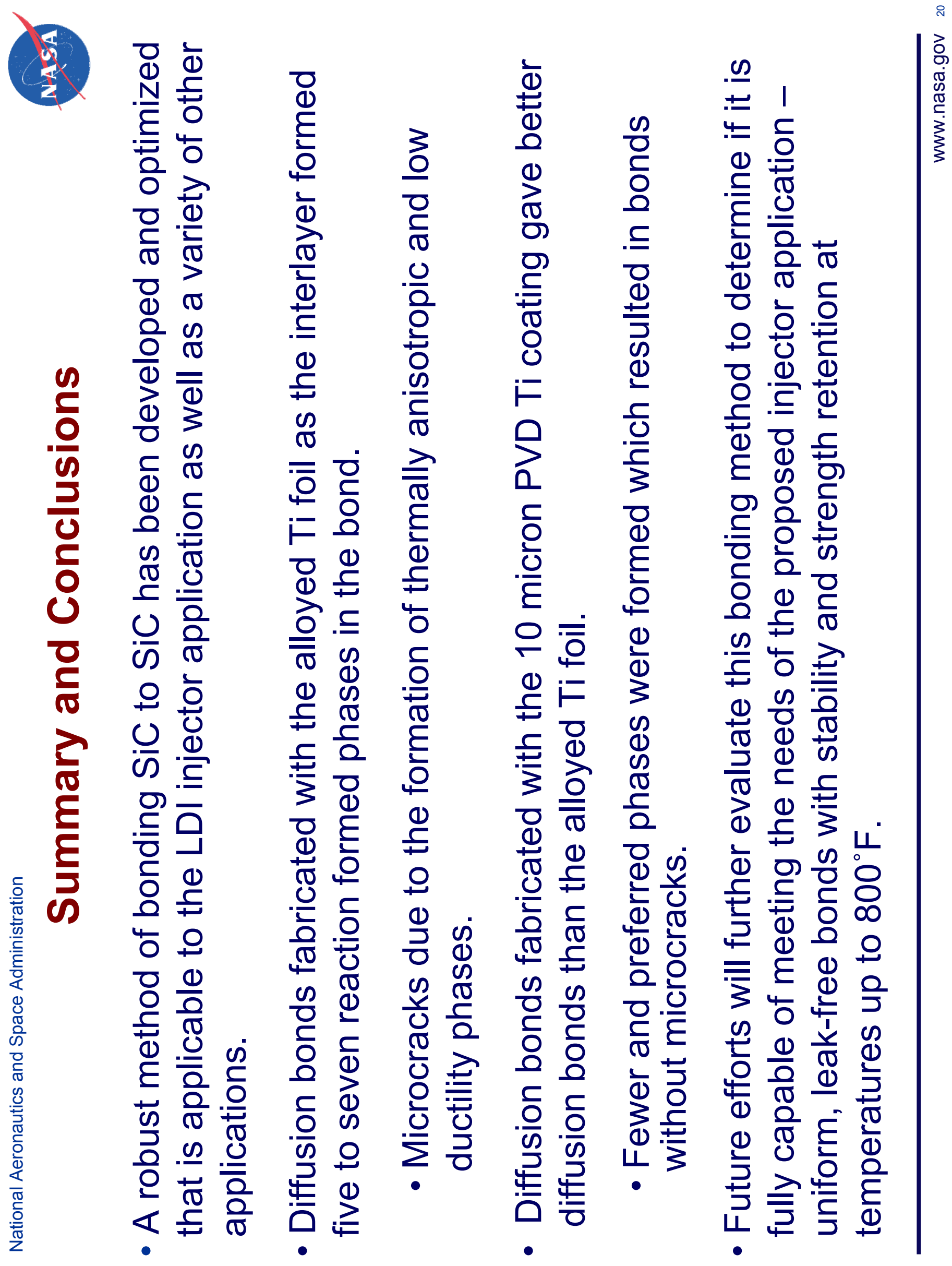

